\title{
AN ASSESSMENT OF THE EFFECT OF PAVEMENT SURFACE CONDITION ON PERFORMANCE OF SIGNALISED INTERSECTIONS
}

\author{
NASREEN HUSSEIN, RAYYA HASSAN \& MICHAEL FAHEY \\ Swinburne University of Technology, Australia
}

\begin{abstract}
This study investigated the effect of pavement surface condition parameters including roughness, rut depth and skid resistance on the operational performance of a sample of signalised intersections i.e. level of service in terms of degree of saturation (DS). Pavement condition data and operational measurements including DS, phase time, cycle time and maximum flow during both AM and PM peak hours were collected for the year before and the year after the time of resurfacing treatments of a sample of intersections. Multiple regression analyses were applied for analysing and assessing intersection performance during AM and PM peak periods, separately and collectively, using the degree of saturation as a response variable with different explanatory variables. Generalised Estimating Equations (GEEs) of Gaussian distribution with an identity link function were used to account for the correlation between repeated observations for a given intersection. Reported in this paper are the statistical analysis approach and findings of the assessment, which indicate that only skid resistance has a statistically significant effect on intersection performance before treatment, where its increase results in a reduction in DS.
\end{abstract}

Keywords: signalised intersection, capacity performance, degree of saturation, roughness, rutting, skid resistance.

\section{INTRODUCTION}

Increasing the capacity of signalised intersections is an important issue and a better understanding of how pavement surface condition (roughness, rutting and skid resistance) and other control factors, affect it helps to propose solutions for improvement. Provided in Table 1 is a summary of findings from past published studies related to the effects of different surface condition parameters on capacity performance. These studies involved using different methodologies and cover different locations (intersections and road links) and operating environments (rural and urban).

Generally, these studies show that the condition of pavement surface does affect the capacity and overall level of service (LOS) of intersections. This might be due to reducing speed and maintaining long distances between vehicles due to a slippery or rough surface, or lane changes to avoid a rough or a certain defect, which in turn result in a reduction in capacity. Further, wet weather condition has been found to exacerbate the effects of poor pavement condition by reducing the available friction between the tyre and road surface. Also water accumulation in ruts or depressions may result in spray and splash from other vehicles which lead to poor visibility.

The aim of the study reported herein is to assess how different pavement condition parameters affect capacity performance of signalised intersections. The sample sites used have been selected to have been subjected to surface treatment. For these sites, surface condition and operational performance data have been collected for the year before treatment and the year after. The approach used involved comparing their performance before and after surface treatment using trend and regression analyses. 
Table 1: Summary of findings from published literature.

\begin{tabular}{|l|l|}
\hline Reference & Findings \\
\hline $\begin{array}{l}\text { Pisano and } \\
\text { Goodwin [13] }\end{array}$ & $\begin{array}{l}\text { Reduction in the available friction between tyre rubber and road } \\
\text { surface and poor visibility result in longer perception time, } \\
\text { longer stopping distance and reduction in cornering capability. }\end{array}$ \\
\hline $\begin{array}{l}\text { Kwon et al., 2013 } \\
{[11]}\end{array}$ & $\begin{array}{l}\text { Increase in road surface condition index (RSI) in terms of } \\
\text { friction causes an increase in capacity and free flow speed. }\end{array}$ \\
\hline $\begin{array}{l}\text { Prevedouros and } \\
\text { Chang [14] }\end{array}$ & $\begin{array}{l}\text { Increase in overall intersection delay and decline in LOS in wet } \\
\text { pavement conditions. }\end{array}$ \\
\hline $\begin{array}{l}\text { Botha and Kruse } \\
\text { [7] }\end{array}$ & $\begin{array}{l}\text { Reduction of saturation flow rate at signalised intersections } \\
\text { during cold winter condition. }\end{array}$ \\
\hline $\begin{array}{l}\text { Asamer and Van } \\
\text { Zuylen [4] }\end{array}$ & $\begin{array}{l}\text { Slippery road condition result in reduction in saturation flow } \\
\text { rate. }\end{array}$ \\
\hline $\begin{array}{l}\text { Rahman and } \\
\text { Lownes [15] }\end{array}$ & $\begin{array}{l}\text { Rainfall and poor visibility results in an increase in the time gap } \\
\text { and decrease in the vehicle speed. }\end{array}$ \\
\hline Chandra [8], [9] & $\begin{array}{l}\text { Increase in pavement surface roughness results in a decrease in } \\
\text { the capacity. }\end{array}$ \\
\hline $\begin{array}{l}\text { Veith [19]; Yu } \\
\text { and Lu [20] }\end{array}$ & $\begin{array}{l}\text { Poor surfaces with high roughness cause a reduction in vehicle } \\
\text { speed. }\end{array}$ \\
\hline Austroads [5] & $\begin{array}{l}\text { Increase in the risk of reduction of friction which will affect } \\
\text { stopping distance, directional control of driver and capacity due } \\
\text { to the accumulated water in the ruts. }\end{array}$ \\
\hline Teply et al. [17] & $\begin{array}{l}\text { Poor pavement condition (deep ruts) causes a reduction in } \\
\text { saturation flow. }\end{array}$ \\
\hline $\begin{array}{l}\text { Rodegerdts et al. } \\
\text { [16] }\end{array}$ & $\begin{array}{l}\text { Poor pavement surface condition at signalised intersections with } \\
\text { and a reduction in capacity. }\end{array}$ \\
\hline
\end{tabular}

\section{ASSESSMENT DATA AND APPROACH}

\subsection{Site selection}

A sample of 35 signalised intersections that were subjected to surface treatment (thin asphalt surfacing) during the period of 2007-2010 were identified. They are from a metropolitan region in Australia. This period was selected as it was the period over which relevant condition data (roughness, rutting and skid resistance) were available for one year before and after treatment years. Further, within this period, data of phase time, maximum flow, cycle time and degree of saturation (DS) for both AM and PM peak hours were available for the same years. The data related to this sample of sites was used in trend and statistical analysis for assessing the effects of surface condition parameters and other situational factors on their performance. It is important to note that post surface treatment (thin asphalt surfacing), no changes were made to the geometry or operating speed of any of these intersections. The only variations were related to surface condition and the normal annual increase in traffic volumes. Further, resurfacing treatments were not applied to the whole intersection. They might cover the intersection centre and/or its approaches (the immediate $200 \mathrm{~m}$ ) and the total length of treatment ranged between 100 and $500 \mathrm{~m}$. 


\subsection{Data preparation}

Surface condition data including roughness, rutting and skid resistance of the treated direction of each site were collected for one year before treatment year and one year after. Roughness is reported in terms of lane IRI (average of two wheel paths) in $\mathrm{m} / \mathrm{km}$ and rut depth in $\mathrm{mm}$ for each $100 \mathrm{~m}$ segment. Both condition parameters are determined from longitudinal and transverse profile measurements. Data of skid resistance are collected for both wheel paths using Side-ways force Coefficient Routine Investigation Machine (SCRIM) and reported for each separately with their average in terms of Side-ways force Coefficient (SFC) values, also for $100 \mathrm{~m}$ segments. Data documented by SCRIM is positive integer equivalent to the $\mathrm{SFC}^{*} 100$.

For the analysis performed herein, data of each condition parameter for each site was averaged over a length of $500 \mathrm{~m}$ covering the intersection centre and a maximum of $400 \mathrm{~m}$ of its approaches. It is important to note that treatments of pavements at intersections and their approaches are currently triggered by surface distress ratings, referred to as Surface Inspection Rating (SIR), regardless of roughness level. SIR of an asphalt surfacing is a composite index of the ratings for cracking, stone loss, texture loss, patching and deformation [21].

SCATS (Signal Coordinated Adaptive Traffic System) data for signalised intersections were used to determine signal operation parameters including signal phase time, degree of saturation, cycle time and maximum flow. The data from the SCATS system covered only these signal operation parameters and were provided for the sites for only one year before and one year after treatment year, during morning peak hours (7-9 am) and afternoon peak hours (4-6 pm). A phase time is the summation of the displayed green time and inter-green time (yellow time plus all-red time) (Akçelik [2]). Cycle time is the sum of phase time for all approaches. The SCATS maximum flow can be defined as "a maximum departure flow rate during a fully saturated green time averaged over the green and inter green times as a special measure of saturation flow rate" (Akçelik [3]).

There are various measures of performance that can be used to express the operational efficiency of signalised intersections (Bennett et al. [6]). Degree of saturation (DS) is one of the major parameters that governs traffic operation at signalised intersections and has been used in this study as a measure of intersection performance. Nguyen [12] reported that at signalised intersections, the pattern of discharge rate is based on the DS. SCATS DS is measured as the green time used by vehicles divided by the available green time (Troutbeck et al. [18]). SCATS DS is one of the measures of effectiveness available from the system. Akçelik [1] discussed SCATS DS parameter in relation to traditional degree of saturation (volume to capacity ratio) and demonstrated the validity of this relationship and accuracy of SCATS DS parameter. Approach DS is the maximum degree of saturation for any lane of the approach considering all lanes used by the movement.

\subsection{Assessment approach}

The effects of the three pavement surface condition parameters on capacity performance were assessed using trend analysis. This was applied to DS in both before and after the year of surface treatment. The assessment approach also included using Generalised Estimating Equation (GEE) with linear regression and identity link function to assess the effect of different explanatory variables including pavement surface condition and other control factors on DS using aggregated data from both AM and PM peak periods i.e. combining AM and PM peaks data in one data set. 


\section{ASSESSMENT RESULTS AND DISCUSSION}

\subsection{Pavement surface condition and DS (degree of saturation) - general trends}

The effects of changes in surface condition including roughness, rutting and skid resistance on intersection capacity performance due to surface treatment are assessed here through observation of trends from graphs. For trend analysis, the data of each condition parameter has been divided into groups or categories, each covering a certain range. DS that corresponds to a certain category is the average of DS values for all intersections with a condition parameter that falls within that category. This approach was applied to both before and after treatment data sets. The reason for adopting this approach is that no clear trends could be observed when plotting DS for each intersection against corresponding condition parameters.

The variations in DS with surface roughness for before and after treatment are presented in Fig. 1 and Fig. 2, respectively. There is generally positive trend where DS increases with roughness and that is true for both before and after treatment data. The variations in DS with rut depth for before and after treatment are presented in Fig. 3 and Fig. 4, respectively. There is a fluctuating relationship between rut depth and DS before and after treatment but indicates that for after treatment the positive trend is more significant than before treatment. The positive trend indicates higher DS where deeper ruts exist. This trend is true for both before and after treatment data, with the only difference, being that the before treatment data set covers deeper ruts than after which is generally expected following a surface treatment.

The relationships between DS and skid resistance in SFC, for before and after treatment are presented in Fig. 5 and Fig. 6, respectively. For both data sets, the relationship fluctuates with respect to the different categories of skid resistance but generally smaller values of DS are associated with higher SFC categories. There is no significant difference in this relationship for before and after treatment except that values of SFC are higher for after $(0.45-0.75)$ treatment than before $(0.35-0.7)$ which is expected due to effect of treatment.

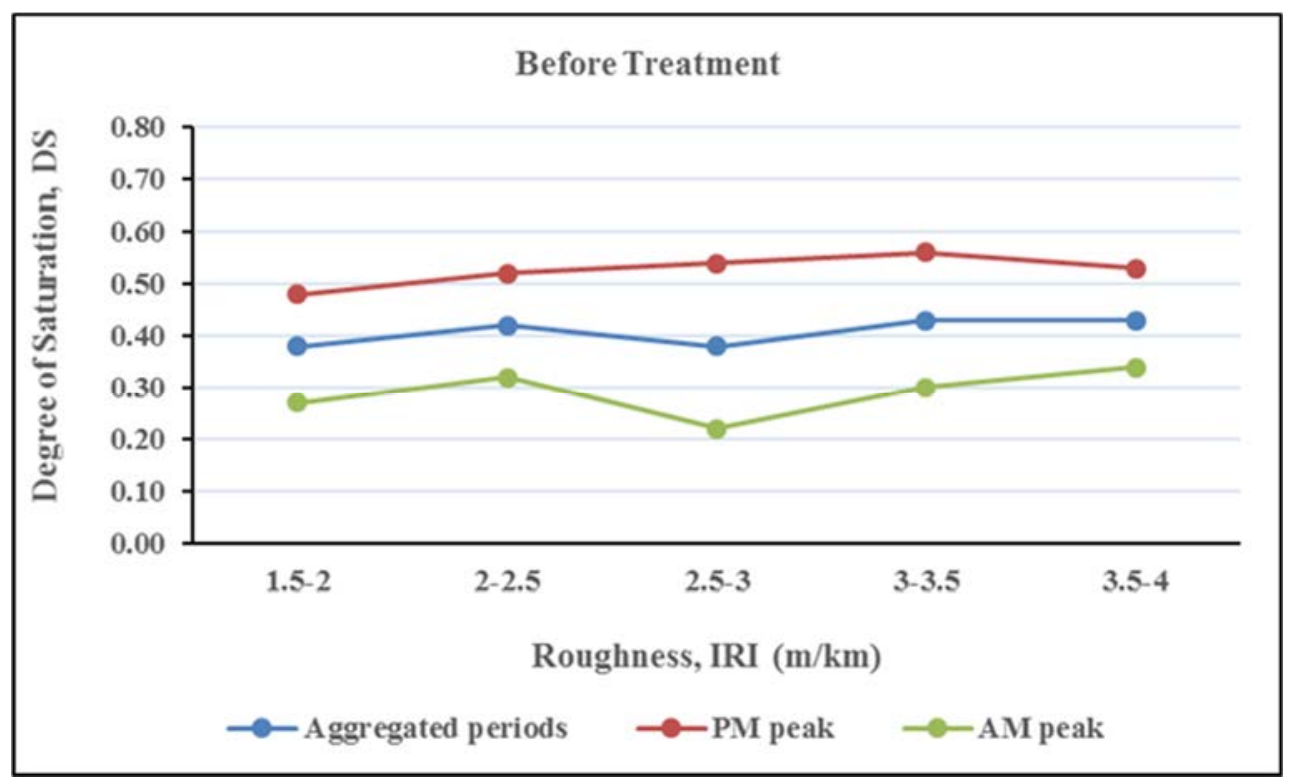

Figure 1: Degree of saturation vs. roughness categories (before treatment). 


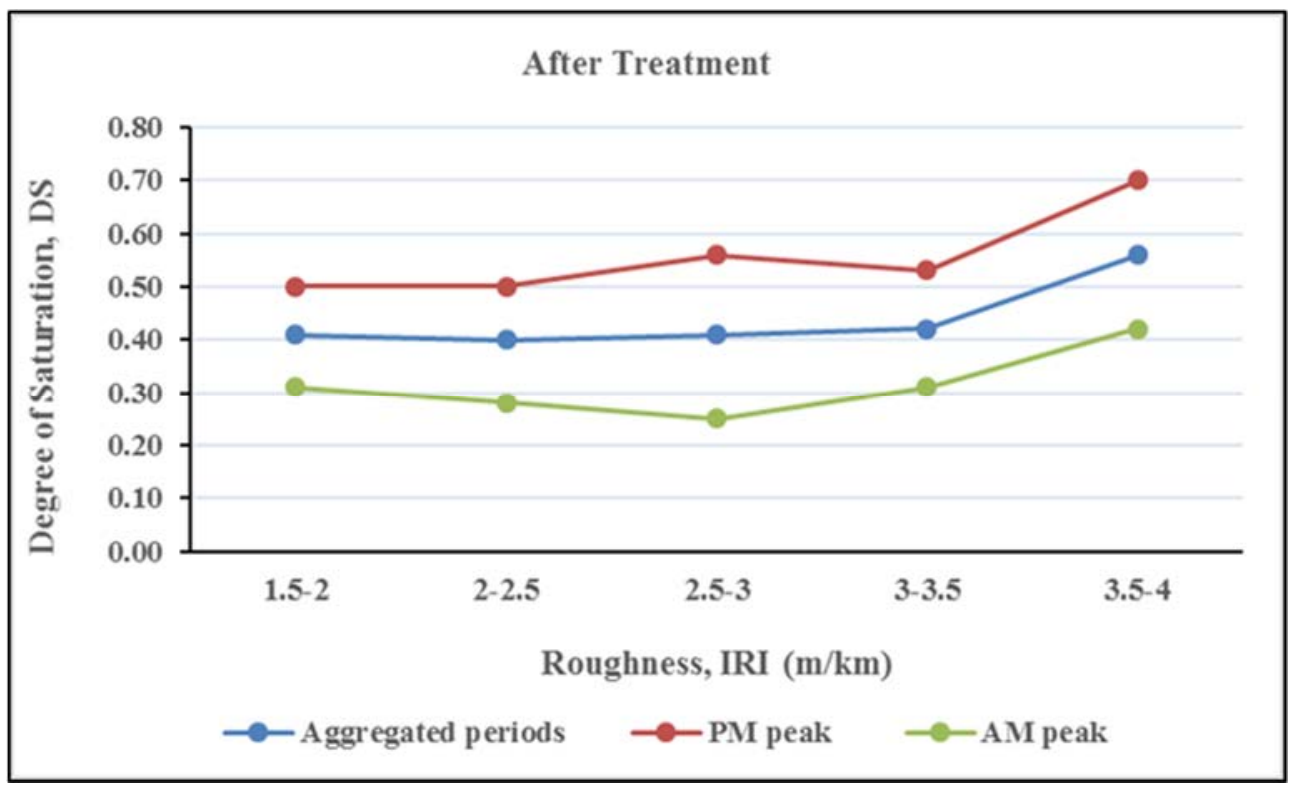

Figure 2: Degree of saturation vs. roughness categories (after treatment).

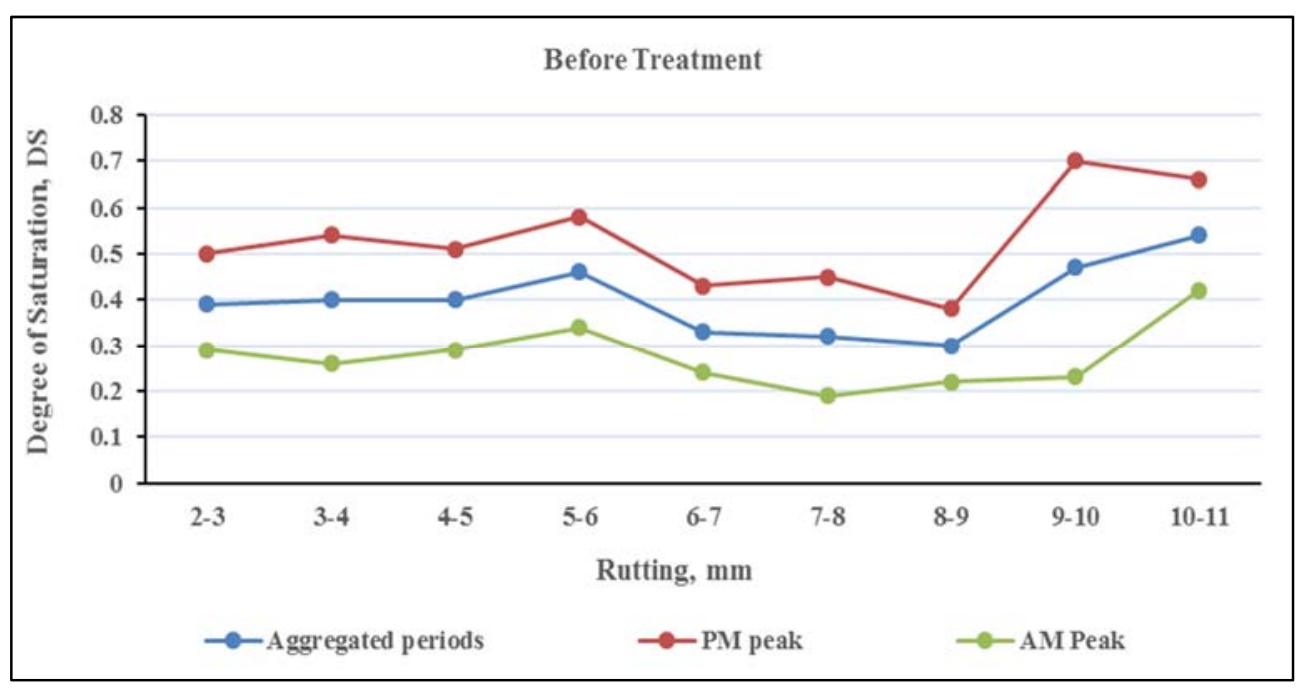

Figure 3: Degree of saturation vs. rutting categories (before treatment). 


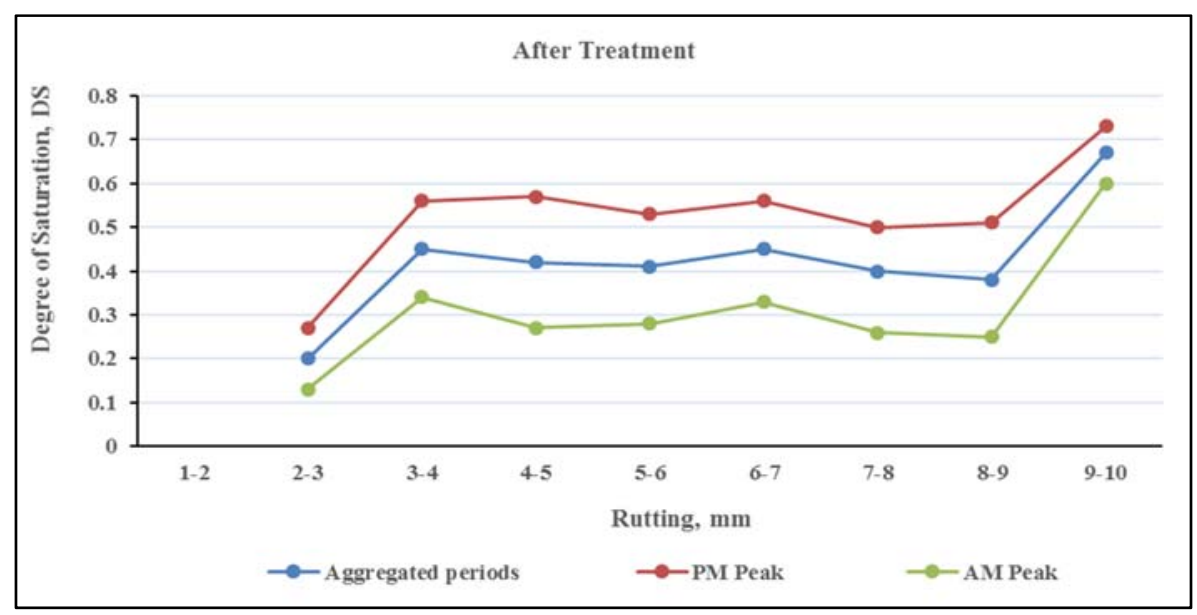

Figure 4: Degree of saturation vs. rutting categories (after treatment).

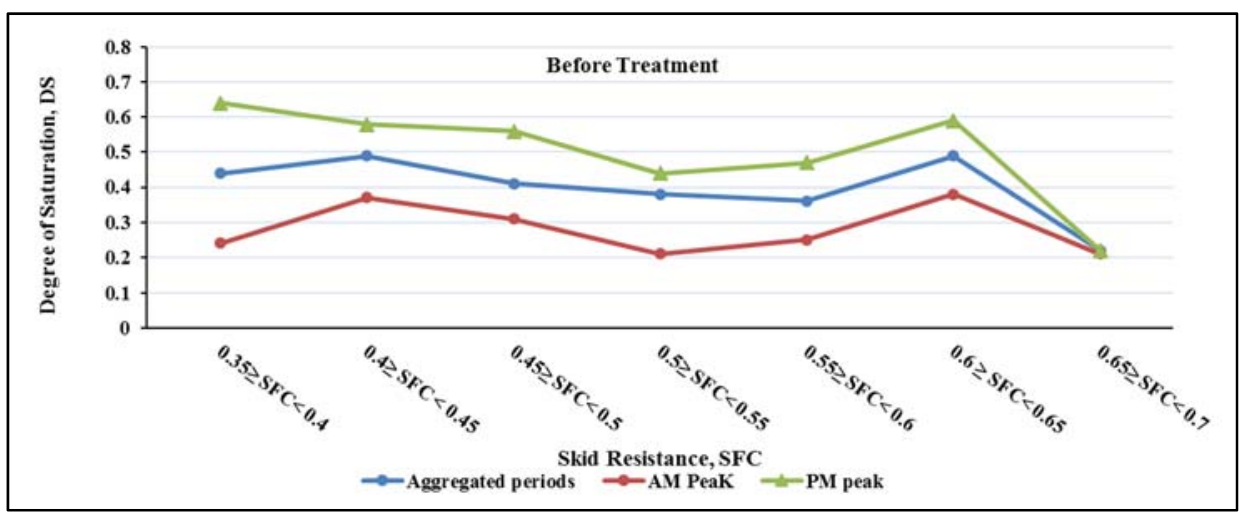

Figure 5: Degree of saturation vs. skid resistance categories (before treatment).

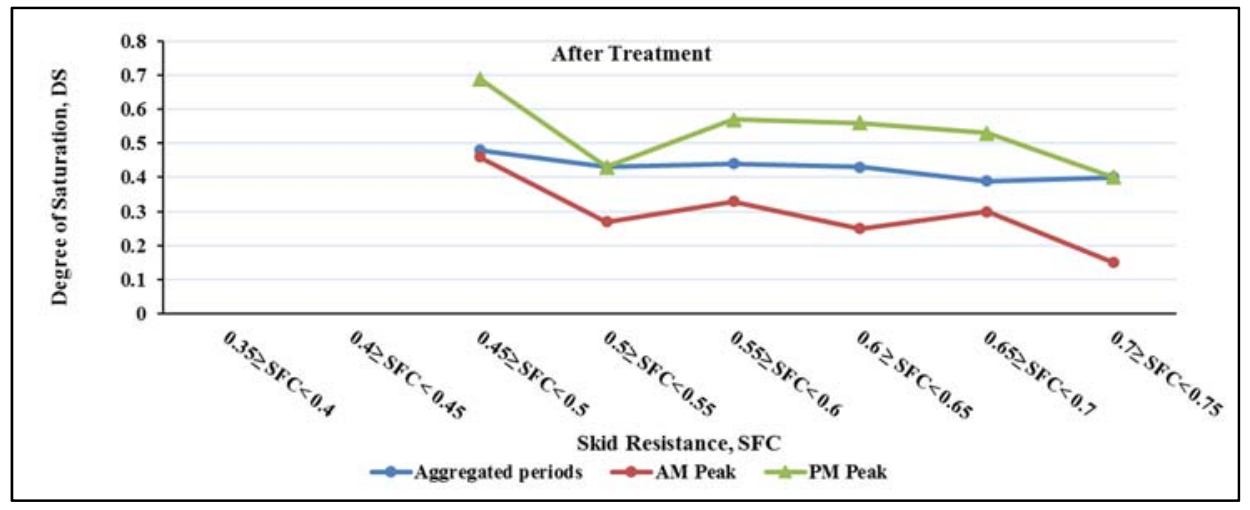

Figure 6: Degree of saturation vs. skid resistance categories (after treatment). 


\subsection{Pavement surface condition and DS (degree of saturation) - statistical analysis}

To evaluate the effect of different factors on capacity performance in terms of DS, considering aggregated data for AM and PM peak hours, DS data was repeated for each site to cover both time periods. This makes the total number of observations $=35 \times 2=70$. This section describes the application of GEE with linear regression and identity link function to analyse DS data as the response variable.

To capture the correlation among the repeated observations, exchangeable correlation structure using robust variance estimation techniques was utilised. The explanatory variables including roughness, rutting and skid resistance were factors of interest in analysing DS data. Maximum flow, peak hour (AM peak coded as 1 and PM peak coded as 0 ), phase time and speed limit were included as control variables. Summary statistics of dependent and continuous independent variables used in this study for before and after treatment are given in Table 2. It is important to note that observations of all explanatory variables for all years before and after treatment are available (no missing values). The continuous independent variables (roughness, rutting, skid resistance, phase time and maximum flow) were centred by subtracting their mean values from their actual values. The results for the GEE regression with identity link function for DS for before and after treatment are given in Table 3 and Table 4 respectively

Results in Table 3 illustrate that not all predictors are statistically significant in explaining the variation in DS. Among them, the main effect of roughness, rutting, phase time and speed limit are not significant to affect DS. However, peak hour (AM peak vs. PM peak), maximum flow and skid resistance are significant in explaining the variation in DS. The correlation estimated by exchangeable structure is 0.364 . This value indicates that the correlation among repeated observations should be accounted for. The intercept is the expected value of DS

Table 2: Descriptive statistics for DS and continuous variables.

\begin{tabular}{|l|c|c|c|c|c|}
\hline Variables & Min & Max & Mean & $\begin{array}{c}\text { Std. } \\
\text { Deviation }\end{array}$ & $\begin{array}{c}\text { Interquartile range } \\
(75 \%-25 \%)\end{array}$ \\
\hline \multicolumn{7}{|c|}{ Before treatment } \\
\hline DS & 0.09 & 0.81 & 0.4126 & 0.184 & $0.58-0.24$ \\
\hline Roughness & 1.55 & 3.99 & 2.9 & 0.69 & $3.56-2.34$ \\
\hline Rutting & 2.50 & 11.60 & 5.83 & 2.29 & $7.2-4.4$ \\
\hline Skid resistance & 0.39 & 0.70 & 0.50 & 0.069 & $0.55-0.47$ \\
\hline Maximum flow & 1405.00 & 2059.00 & 1816.23 & 148.15 & $1937.25-1713.25$ \\
\hline Speed limit & 60.00 & 80.00 & 71.14 & 6.60 & $80-70$ \\
\hline Phase time & 17.00 & 84.00 & 41.53 & 16.17 & $49.75-29.75$ \\
\hline \multicolumn{7}{|c|}{ After treatment } \\
\hline DS & 0.13 & 0.83 & 0.42 & 0.177 & $0.57-0.27$ \\
\hline Roughness & 1.81 & 3.86 & 2.85 & 0.528 & $3.26-2.45$ \\
\hline Rutting & 2.80 & 9.80 & 4.91 & 1.57 & $5.6-3.8$ \\
\hline Skid resistance & 0.48 & 0.71 & 0.60 & 0.056 & $0.65-0.58$ \\
\hline Maximum flow & 1568.00 & 1985.00 & 1781.90 & 118.16 & $1860.25-1676.75$ \\
\hline Speed limit & 60.00 & 80.00 & 71.14 & 6.60 & $80-70$ \\
\hline Phase time & 17.00 & 87.00 & 40.07 & 17.07 & \\
\hline
\end{tabular}


Table 3: GEE with linear regression and identity link for log DS-before treatment.

\begin{tabular}{|l|c|c|c|c|c|c|}
\hline & \multirow{2}{*}{$\begin{array}{c}\text { Coefficient } \\
\beta)\end{array}$} & $\begin{array}{c}\text { Std. } \\
\text { Error }\end{array}$ & P-Value & Exp $(\beta)$ & \multicolumn{2}{|c|}{$\begin{array}{c}\text { 95\% Wald Confidence } \\
\text { Interval for Exp }(\beta)\end{array}$} \\
\cline { 6 - 7 } & -1.232 & 0.099 & 0.000 & 0.292 & 0.24 & 0.35 \\
\hline Intercept & 0.643 & 0.067 & 0.000 & 1.902 & 1.667 & 2.170 \\
\hline Peak hour, PM=0 & 0 &. &. & 1 &. &. \\
\hline Peak hour, AM=1* & 0.113 & 0.092 & 0.218 & 1.120 & 0.935 & 1.341 \\
\hline Roughness & 0.001 & 0.022 & 0.979 & 1.001 & 0.959 & 1.044 \\
\hline Rutting & -0.019 & 0.007 & 0.003 & 0.981 & 0.969 & 0.994 \\
\hline Skid Resistance $\times 100$ & 0.161 & 0.043 & 0.000 & 1.174 & 1.079 & 1.279 \\
\hline Maximum Flow/100 & 0.000 & 0.003 & 0.965 & 1.000 & 0.995 & 1.005 \\
\hline Phase Time & -0.074 & 0.079 & 0.353 & 0.929 & 0.796 & 1.085 \\
\hline Speed Limit & 0.111 & & & & & \\
\hline Scale & & & & & & \\
\hline
\end{tabular}

Table 4: GEE with linear regression and identity link for log DS-after treatment.

\begin{tabular}{|l|c|c|c|c|c|c|}
\hline & & \multirow{2}{*}{ Parameter } & \multirow{2}{*}{$\begin{array}{c}\text { Coefficient }(\beta) \\
\text { Error }\end{array}$} & P-Value & Exp $(\beta)$ & \multicolumn{2}{|c|}{$\begin{array}{c}\text { 95\% Wald Confidence } \\
\text { Interval for Exp }(\beta)\end{array}$} \\
\cline { 5 - 7 } & & & & Lower & Upper \\
\hline Intercept & -1.234 & 0.091 & 0.000 & 0.291 & 0.244 & 0.348 \\
\hline Peak hour, PM=0 & 0.669 & 0.059 & 0.000 & 1.953 & 1.739 & 2.192 \\
\hline Peak hour, AM=1* & 0 &. &. & 1 &. &. \\
\hline CRoughness & 0.122 & 0.102 & 0.228 & 1.130 & 0.926 & 1.379 \\
\hline Rutting & 0.017 & 0.039 & 0.668 & 1.017 & 0.942 & 1.098 \\
\hline Skid Resistance*100 & -0.004 & 0.009 & 0.689 & 0.996 & 0.979 & 1.014 \\
\hline Maximum Flow/100 & 0.115 & 0.037 & 0.002 & 1.122 & 1.043 & 1.207 \\
\hline Phase Time & -0.002 & 0.003 & 0.439 & 0.998 & 0.993 & 1.003 \\
\hline Speed Limit & -0.048 & 0.074 & 0.515 & 0.953 & 0.824 & 1.102 \\
\hline Scale & 0.097 & & & & & \\
\hline
\end{tabular}

when all variables in the model are evaluated at zero. That is, during AM peak, the expected value of DS is $\exp (-1.232)=0.292$ for an intersection with a speed limit of $60 \mathrm{~km} / \mathrm{h}$, if all other centred variables take their mean values. The effect of categorical variables can be interpreted using $\exp (\beta)$, in which, $\exp (\beta)$ is the multiplicative change in the geometric mean (GM) of the dependent variable per unit change in predictors. The geometric mean can be defined as "the average of the logarithmic values of a data set, converted back to a base 10 number" (Costa [10]).

The effect of period of day indicates that the GM for DS at PM peak is 1.9 times greater than AM peak. With a small range of skid resistance from 0.39 to 0.7 , the effect of skid resistance $\times 100$ was used to increase the interpretability of regression coefficients. Therefore, interpretation in terms of 0.01 increase in skid resistance is preferred rather than 1 -unit increase. The effect of skid resistance exhibits that a 0.01 increase in skid resistance in SFC results in a reduction in the DS by exp $(-0.019)=0.98$ or by $2 \%(1-0.98)$. This is because an increase in skid resistance (better road condition), cause drivers to drive at higher speeds and this results in a reduction in clearance distance which is kept by drivers. Similar 


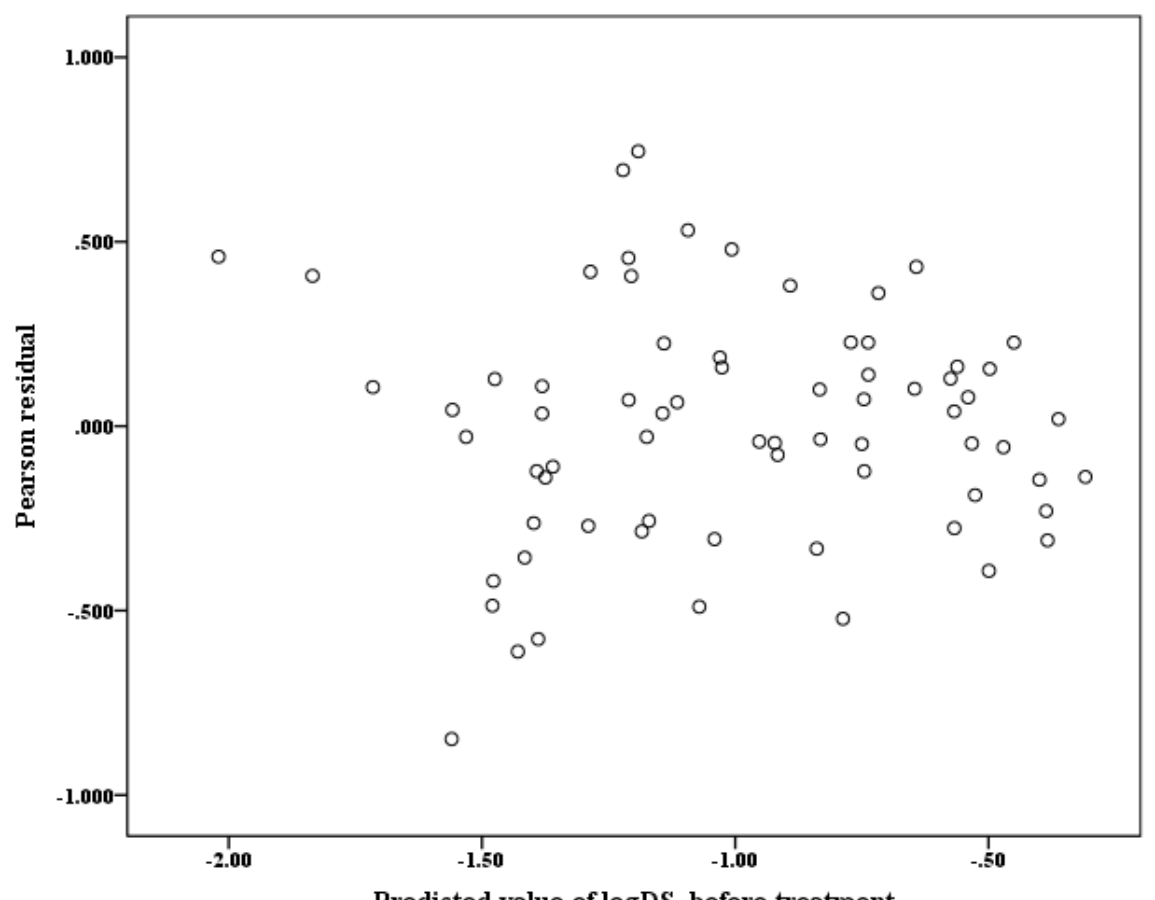

Predicted value of $\log \mathrm{DS}$, before treatment

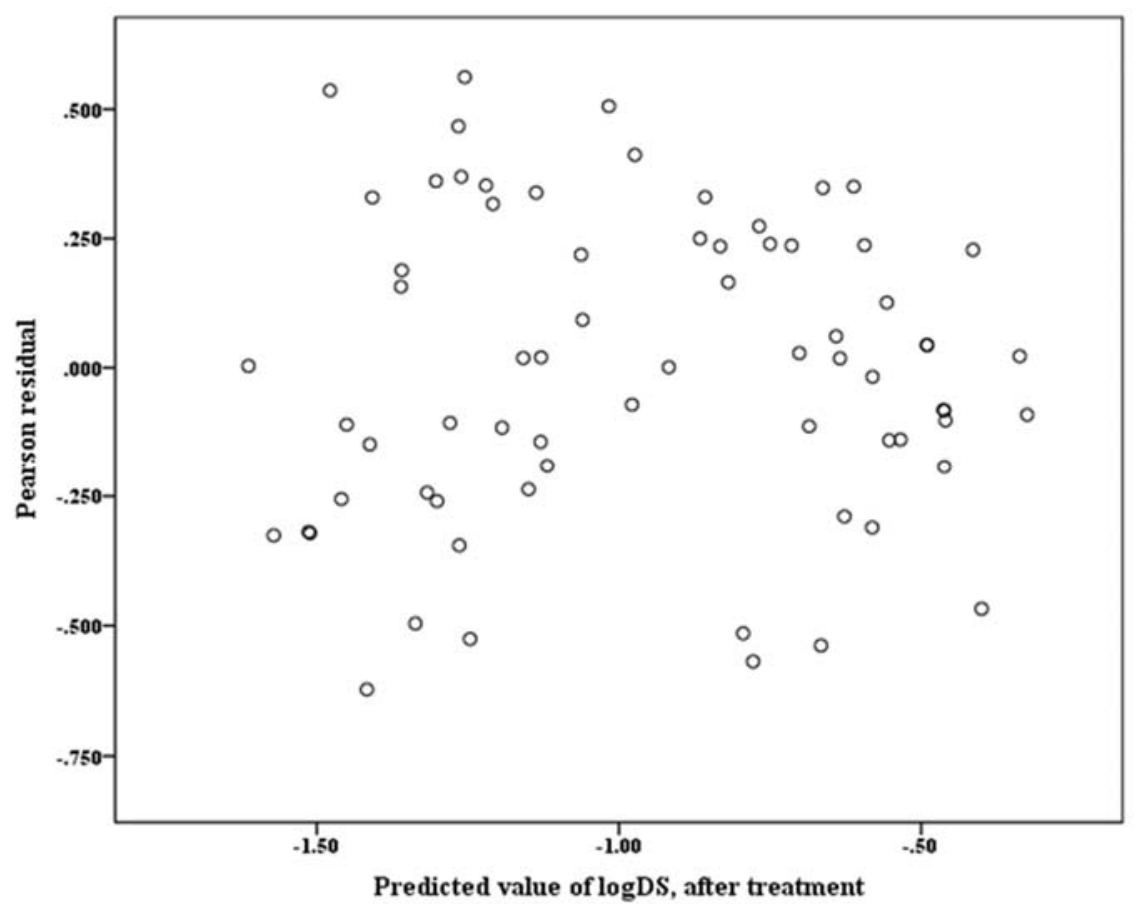

Figure 7: Residuals vs. predicted value of $\log \mathrm{DS}$, before and after treatment. 
findings are reported by (Asamer and van Zuylen [4]; Kwon et al. [11]). Furthermore, to increase the interpretability of regression coefficients for maximum flow, the effect of maximum flow/100 was used. Therefore, interpretation in terms of 100-unit increase in maximum flow is preferred rather than 1-unit increase. The effect of maximum flow exhibits that for each 100 units increase in maximum flow in $\mathrm{veh} / \mathrm{h}$ the DS increases by exp $(0.161)$ $=1.174$ or by $17.4 \%$. The results are expected, as an increase in the volume of traffic flow at approaches of signalised intersections during peak hours results in a reduction in the speed of vehicles and therefore, increase the degree of saturation.

Results in Table 4 illustrate that not all predictors are statistically significant in explaining the variation in DS. Among them, the main effect of roughness, rutting, skid resistance, phase time and speed limit are not significant to affect degree of saturation. However, peak hour (AM peak vs. PM peak) and maximum flow are found to be significant in explaining the variation in DS. The correlation estimated by exchangeable structure is 0.444 . This value indicates that the correlation among repeated observations should be accounted for. The intercept is the expected value of DS when all variables in the model are evaluated at zero. That is, during AM peak, the expected value of DS is $\exp (-1.234)=0.291$ for an intersection with a speed limit of $60 \mathrm{~km} / \mathrm{h}$, if all other centred variables take their mean values. The effect of period of day indicates that the GM for DS at PM peak is 1.95 times greater than AM peak. The effect of maximum flow exhibits that for each 100 increase in maximum flow in veh $/ \mathrm{h}$ the DS increases by exp $(0.115)=1.122$ or by $12.2 \%$. The reason for this trend is the same as that for before treatment.

\subsection{Model evaluation}

To assess whether the selected model adequately fits the data, Pearson residuals were plotted against predicted value of $\log \mathrm{DS}$ for both before and after treatment as given in Fig. 7 . The figure shows that $95 \%$ of the residuals fall within -1 and +1 . However, for both before and after treatment there is a slight tendency of non-constant variance (heteroscedasticity) and it is more pronounced for before treatment data. It is believed that this would have very limited effect on the accuracy and reliability of the model.

\section{SUMMARY AND CONCLUSIONS}

The effects of different explanatory variables including pavement surface condition and other control factors on the degree of saturation (DS) using aggregated data from both AM and PM peak periods indicate that pavement surface treatment has the tendency to alter DS. Based on the general trends of pavement surface condition parameters and degree of saturation (DS), the following findings can be drawn:

- The variation in DS with surface roughness for both before and after treatment indicates that there is generally a positive trend where DS increases with roughness and that this is true for both before and after treatment data.

- There is a fluctuating relationship between rut depth and DS in before and after treatment. For after treatment the positive trend is more significant than before treatment indicating higher DS where deeper ruts exist.

- The relationship between DS and the different categories of skid resistance (in SFC) for before and after treatment fluctuates but generally smaller values of DS are associated with the higher SFC categories.

The key findings from the statistical analysis of degree of saturation are as follows: 
- For both before and after treatment, the effect of period of day is significant and indicates that the GM (geometric mean) for DS at PM peak is greater than that of AM peak.

- For both before and after treatment, the increase in maximum flow results in an increase in degree of saturation.

- For before treatment, an increase in skid resistance results in a reduction in DS.

\section{REFERENCES}

[1] Akçelik, R., Fundamental traffic variables in adaptive control and the SCATS DS parameter. International Conference of ITS Australia, 3rd, Brisbane, Australia, 1997.

[2] Akçelik, R., SIDRA Intersection User Guide, Akcelik, R. and Associates Pty, Greythorn, Australia, 2006.

[3] Akçelik, R., SIDRA Intersection User Guide, Akcelik, R. and Associates Pty, Greythorn, Australia, 2012.

[4] Asamer, J. \& van Zuylen, H.J., Saturation flow under adverse weather conditions. Transportation Research Record: Journal of the Transportation Research Board, 2258, pp. 103-109, 2011.

[5] Austroads, Urban road design: a guide to the geometric design of major urban roads. AP-G69/02, Sydney, Australia, 2002.

[6] Bennett, D. et al., Guide to traffic management part 3: traffic studies and analysis. AGTM03/13, Austroads, Sydney, Australia, 2013.

[7] Botha, J.L. \& Kruse, T.R., Flow rates at signalized intersections under cold winter conditions. Journal of Transportation Engineering, 118, pp. 439-450, 1992.

[8] Chandra, S., Capacity estimation procedure for two-lane roads under mixed traffic conditions. J. Indian Roads Congress, pp. 139-170, 2004.

[9] Chandra, S., Effect of road roughness on capacity of two-lane roads. Journal of Transportation Engineering, 130, pp. 360-364, 2004.

[10] Costa, J., Calculating Geometric Means, Buzzards Bay National Estuary Program East Wareham, Massachusetts, 2007, Online. http://buzzardsbay.org/geomean.htm. Accessed on: 30 May 2016.

[11] Kwon, T., Fu, L. \& Jiang, C., Effect of winter weather and road surface conditions on macroscopic traffic parameters. Transportation Research Record: Journal of the Transportation Research Board, pp. 54-62, 2013.

[12] Nguyen, H., Comparison of discharge patterns at traffic signals. Transportation Research Board 85th Annual Meeting, Washington DC, USA, 2006.

[13] Pisano, P. \& Goodwin, L.C., Surface transportation weather applications. In Federal Highway Administration in Concert with Mitretek Systems. Presented at the 2002 Institute of Transportation Engineers Annual Meeting, 2002.

[14] Prevedouros, P.D. \& Chang, K., Potential effects of wet conditions on signalized intersection LOS. Journal of Transportation Engineering, 131, pp. 898-903, 2005.

[15] Rahman, A. \& Lownes, N.E., Analysis of rainfall impacts on platooned vehicle spacing and speed. Transportation Research Part F: Traffic Psychology and Behaviour, 15, pp. 395-403, 2012.

[16] Rodegerdts, L.A. et al., Signalized intersections: informational guide. FHWA, U.S. Department of Transportation (Publication FHWA-HRT-04-091), Washington, D.C., 2004.

[17] Teply, S., Allingham, D., Richardson, D. \& Stephenson, B., Canadian capacity guide for signalized intersections. Institute of Transportation Engineers, District 7, Canada, 2008. 
[18] Troutbeck, R., Su, M. \& Luk, J., National performance indicators for network operations. $A P-R 305 / 07$, Austroads, Sydney, Australia, 2007.

[19] Veith, G., Guide to road design part 4A: unsignalised and signalised intersections. AGRD04A/10, Austroads, Sydney, Australia, 2009.

[20] Yu, B. \& Lu, Q., Empirical model of roughness effect on vehicle speed. International Journal of Pavement Engineering, 15, pp. 345-351, 2014.

[21] VicRoads, Surface Inspection Rating Procedure For Pavements Surfaced with Sprayed Seals and Asphalt, VicRoads: Melbourne, 2004. 